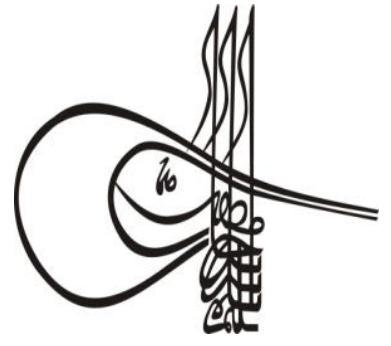

Received/Geliş: 26.08.2019
Turkigh Studies

Social Sciences

Volume 14 Issue 5, 2019, p. 2069-2084

DOI: 10.29228/TurkishStudies.32673

ISSN: 2667-5617

Skopje/MACEDONIA-Ankara/TURKEY

Research Article / Araştırma Makalesi

ArticleInfo/Makale Bilgisi

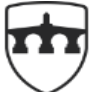

INTERNATIONAL BALKAN UNIVERSITY

EXCELLENCE FOR THE FUTURE IBU.EDU.MK

\title{
ALEVİ KÜLTÜREL KİMLİĞİNDE BAĞLAMANIN YERİ VE ÖNEMI
}

\author{
Yusuf BENLí⿱艹
}

\section{öz}

Dünya tarih sahnesinde pek çok kültür zamana yenik düşerken Alevi kültürünün varlığını bugün sürdürebilmesinde, bağlama öncü ve taşıyıcı bir rol üstlenmiştir. Alevi müziği saz ve söz birlikteliği üzerine kurulmuştur. Öğretinin kültürel kimliğinin korunması, yaşatılması, geleceğe aktarılması ve yeniden inşasında bağlama, bir çalgı olmanın ötesine geçerek çok önemli bir tarihi görevi yerine getirmiştir. AleviBektaşi öğretisi, hoşgörü temelinde yaşamda değişime açık bir düşünce ve inanç anlayışı içinde "benim kâbem insandır" ilke ve felsefesiyle insanın düşünce dünyasına 1şık tutmuştur. Bu doğrultuda bağlamanın yüzyıllar boyunca, Alevi öğretisinin hedeflediği İnsan-1 Kâmil olma amacına sanat ile nasıl araçlık yaptığını ortaya koymak çalışmanın temel hedefini oluşturmaktadır. Çalışma kapsamındaki bilgilerin elde edilmesinde kaynak taraması, katılımlı ve yönlendirilmiş gözlem yöntemleri kullanılmıştır. Alevi kültürü içerisinde bağlamanın yerinin oldukça kutsal ve önemli olduğu, "Telli Kur’an” benzetmesi, "aşı̆̆ın sözü Kur’anın özü" ve "ayn-i cem bülbülü" gibi betimlemeler ile belirgin bir şekilde ifade edilmiștir. Sözlü kültür üzerinden oluşturulan kültürel belleğin temel taşıyıcısı olan bağlama, aynı zamanda insanın kendini ifade etmesi, toplumsallaşmas1, iletişim kurmas1, düşünmesi ve düşünceyi aktarmasına da bir biçimde araçlık yapmıştır. Asırlar boyunca Alevi toplumunun kendini ifade etmesinde, kültürünü canlı tutmasında, bağlamanın çok önemli bir rol üstlenmiş olduğu ve bu toplumun fertlerinin düşünen beyni, çarpan yüreği haykıran dili olduğu görülmüştür. Sonuç olarak elde edilen veriler 1şığında bağlamanın Anadolu Alevi kültürel kimliğinin oluşmasına, tekrarlayan öğretiler yoluyla aktarılmasına, yaygınlaşmasına ve yeniden inşasına önemli derecede etkisi ve katkısı olduğu tespit edilmiştir. 
Anahtar Kelimeler: Bağlama, Alevi Kültürü, Alevi Müziği, Kültürel Kimlik.

\title{
THE STATUS AND SIGNIFICANCE OF BAGLAMA IN THE CULTURAL IDENTITY OF ALEVI COMMUNITY
}

\begin{abstract}
While numerous civilizations could not survive in time throughout the history, Alevi culture maintains its existence and in this regard, the instrument bağlama played a primary role in its transfer to other generations. Alevi-music is founded on the unity of bağlama and lyrics. Having passed beyond its instrumental character, baglama played a very important historical role in the preservation, reproduction, transferring and reconstitution of the cultural identity of Alevi communities. Alevi-Bektashi teachings has illuminated the world of thought of the mankind with the principle and philosophy of "My Kaaba is the human", based on tolerance, and in an understanding of idea and faith open to evolution in life In this context, the primary goal of this work is to demonstrate how baglama became an intermediary instrument between forms of art and the purpose to be İnsan-1 Kâmil [Perfect Human] as Alevi doctrines taught for centuries. The information and data in this study were gathered by different methodologies such as literature reviewing, participant and controlled observations. The sacred and venerable status of this instrument in Alevi culture clearly shows itself in phrases like "Telli Kur'an" [Stringed Quran], "aşığın sözü Kur'anın özü" [minstrel's word is Quran's essence], "ayn-i cem bülbülü" [nightingale of cem rituals] that linking baglama with holy book of Islam and rituals in Alevi religion. Baglama has been the primary tool to transfer cultural memory through oral culture and at the same time allowed people to express themselves, to socialize, to communicate, to think and to share their thoughts with others. For centuries baglama was a crucial element in the self-expression of Alevi community and reproduction of this culture. In fact, this instrument became the thinking mind and crying heart of its community. In the light of collected data, it is clearly seen that baglama has a significant role in the generation of Anatolian Alevi culture, in transfer of its teachings and their reconstruction.
\end{abstract}

\section{STRUCTURED ABSTRACT}

The purpose of this study is to display the place and importance of baglama in Alevi-Bektashi culture and to draw attention to the process of a cultural identity being constructed, kept alive, conveyed and spread. The purpose is also to establish that art is an important tool for the goal of society-engineering. The study uses literature review, field study and observation methods.

The first written samples of music in Anatolia belongs to Sumerians. It is assumed that music, as a cultural element, has surfaced in synchronization with history of humanity. When we view humanity's philosophical and intellectual progress from a historical 
perspective, the relation between society and music has been important since the first ages. Classical era philosopher Platon states that music is a central element of his idea of an ideal government. He also states that it is one of the most important tools for individual development and that music educates the soul. Aristoteles relates music to the concept of Katharsis, meaning cleansing and refinement, pointing to music as a reference for the individual to reach true virtue, direct themselves to good and educate themselves.

Music is important and special for every culture, and it is one of the basic elements of culture. Its witnessing of history and ability to preserve itself is much more significant regarding its functionality. Thus music is one of the most important keys in understanding culture and cultural identity.

Music is the construction, conveying and spreading tool of AleviBektashi philosophy and belief system which has its distinctive rituals. Hac1 Bektash Veli is the founder of a philosophy and belief system that proposes and organizes a change in lifestyle based on humanism and tolerance and shed light on this path with his principle and philosophy of "My Kaaba is human."

Alevi music is founded upon the union of instrument and vocal. The basic element that establishes its literal context is its wording structure that carries the codes of the teachings. This structure tells the historical progress, philosophical and mythological context of the teachings in the form of poems. Its musical context is created by troubadours (aşık), singing poets (ozan) and singing dervishes (zakir) by baglama building upon the poem style literal structure. Baglama has developed and changed under the influence of many cultures in Anatolia, and it has become an instrument unique to Anatolia and Anatolian people with its construction, playing style and emotion.

Baglama has spread over a wide geographical area and a timeline of centuries with regards to depth and spread in time and space. It has different forms and names across Balkans to Caucasus and Middle Asia but it has become an indispensable part of Turkish culture with the name of "saz". Baglama is the main instrument of Alevi music, and it conveys the message it carries in the context of artistic communication to the receiver in the visual, audial and emotional sense. It reinforces the content meaning of the message with musical emotion and creates a spiritual atmosphere, enabling it to be perceived and retained in memory. In this artistic communication process, it was tried to create the cultural memory of the teaching through oral culture and transfer it to the future through the works and rituals which are the key words of the repeated teaching accompanied by the binding of the minstrels, poets and zakir of Alevi-Bektashi culture.

The playing and singing of the works that carry the codes of the teachings, which is one of the most basic components of Alevi culture for centuries, has played an important role in the revitalization, transfer and representation of the culture. Alevi culture has created a unique style in these three different branches of art in music, poetry and dance traditions. Due to the deep world of meaning and the accumulation of poetry and music embedded in diversity, it has created a rich heritage based on context. 
In the Alevi teachings, the sacred qualities attributed to baglama are expressed as follows. "The tekne (body) of baglama is the way to find hidden science and God. For this reason, this part is called 'City of Science'. The göğüs (chest) makes sounds, and this göğüs is the door that prevents the disintegration and loss of the hidden sciences on the tekne. Since the threshold is already sacred in Alevism, the essik (threshold) of baglama is therefore of particular importance. The sap (handle) in the form of Elif is to refer to Ali and Allah because of this form. The reference sound on the baglama, A pitch is called the "şah perdesi" (shah pitch). Among the F, G, H sounds that are used to find the intermediary epistles, the first two are the pitches for remembering and search so they are named "niyaz perdesi" (invocation pitches). The Alevis call saz as "Telli Kuran" (Quran with strings) for mediating the wise words of minstrels and bards. From heart to hand, from hand to string, from string to tongue and from tongue to hearth cycle returns to şah perdesi (reference pitch). "

In Alevi culture, baglama has shown a fundamental functionality in the field of cultural transfer in the first stage and cultural diffusion in the second stage. It has carried out the cultural transfer process through cem rituals and mekteb-i irfan (school of knowledge) conversations in the doctrinal context. With the awareness of the internalization of music and literature in the practice of life, the cultural prevalence was made through the works of the teachings that has been taught by the performance artists in the performance level of the Alevi teachings.

In addition, the fact that a father in Amasya, in an Alevi village, requires his son to learn how to play baglama in order to grant his wish is one of the biggest manifestation of how a real weapon is destroyed with baglama and Alevi teachings, creates a wise person and a peaceful community through art.

Upon an examination of the place and importance of baglama in Alevi cultural identity, it is established that Alevi philosophy, which puts people at the core, shows an artistic existence through a lifestyle formed by synthesis of belief and culture, and Alevi teachings has taken its place within the world philosophical history with its thought, philosophy, music, literature, poetry, folklore and human values.

In Alevi teachings, it is understood that baglama is one of the most fundamental elements of the ritual due to the fact that the cem is performed with the instrument and music, and its effects on human emotions. In the cem rituals of Alevi culture, the identity, personality, intellectual and belief development of the individual is ensured along with the cultural conveyance. It has been understood that baglama is one of the fundamental carriers in transference and widespread adoption of Alevi culture through artistic communication and cem rituals.

It has been concluded that baglama is a 'symbol' that represents the cultural identity of Alevis due to its position in the doctrine, its mission and functionality. It has been seen that the verbal component is the common denominator of Alevi music which is caused by regional differences. 
It has been concluded that the sacredness of baglama in Alevi culture is for the reason that it enables $\mathrm{Hz}$. Ali, The Twelve Imams and Ehl-i beyt, the most fundamental symbols of Alevi cultural identity, to be kept alive and convey their wisdom in the artistic works by playing and singing about them.

It has been observed that baglama is much more than a musical instrument in Alevi cultural identity; that it plays a significant and large role in conveying the Alevi teachings, through art and thus creating wise people and a peaceful community.

Keywords: Baglama, Alevi Culture, Alevi Music, Cultural Identity.

\section{Giriş}

Sosyal evrim süreci içinde insan, bedensel ve ruhsal olarak pek çok farklı nitelikler kazananır ve soya çekimle de kendi türüne özgü özellikler taşır. Kalıtım yolu ile kuşaktan kuşağa aktarılan bu özellikler bugünün insanına yüzlerce, binlerce yıl öncesinden gelmiş olup günümüz insanı ile de yüzlerce, binlerce yıl sonrasına aktarılacaktır.

İnsanın kalıtım yoluyla anne ve babadan gelen gen gruplarıyla bedensel ve ruhsal yaşamının alt yapısı oluşur. Bu altyapı hem kişinin özgün gelişmini hem de başka insanlardan farklılığını sağlar. Özel donanımlar vasıtasıyla da kimliği ortaya çıkar. İnsanın davranışları, doğadan yansıyan etkiler ve insan türünün oluşturduğu çevre koşulları içinde biçimlenir (Köknel, 1983, s: 31).

Eğitim ve kültürlenme, bireyin davranışlarında kendi yaşantısı yoluyla istendik yönde değişim meydana getirme sürecidir. Bu sürecin temel unsurlar1, aile, okul ve çevredir. Birey ait olduğu toplumsal yapı içerisinde kendi sürecini inşa eder ve kültürel kimliğini oluşturur. Yaşadığı ve yetiştiği toplum üzerinden sosyal kimliği oluşan birey, iletişim içinde olduğu her ortamda davranışlarını ve ilişkilerini farkına varmadan bunun üzerinden oluşturur.

İki yüze yakın farklı bağlamlar üzerinden kültür tanımı yapılmıştır. İşlediğimiz konu bağlamı açısından Bozkurt Güvenç'in "İnsan ve Kültür, Atropolojiye Giriş" çalışmasında aktarmış olduğu ve kültürü ele alan bazı tanımlar şunlardır:

Dilbilimci ve etnolog Edward Sapir'e göre "Sosyal miras ve geleneksel sistem üzerinden kültür; varlı̆̆ımızın yapısını (dokusunu) belirleyen sosyal bir süreçle öğrendiğimiz uygulama ve inançların, maddi ve manevi öğelerin birliğidir". Linton'a göre "Kültür, bir toplumun hayat biçimidir". Maquet'e göre "Kültür, bir grubun yaşama biçimidir". Tozzer'e göre "Eğitim bağlamında kültür, toplumsal olarak öğrenilen ve aynı yolda yeni kuşaklara iletilen davranış örüntüleri (kalıpları)'dir". Winston'a göre "Oluşumu ve kökeni bağlamında kültür, soyal etkileşimin ürünüdür". Herskovits'e göre "Kültür, çevremizin insan yapısı olan kısmıdır". Marx'a göre ise "Kültür doğanın yarattıklarına karşılık, insanoğlu'nun yarattığı her şeydir" (Güvenç, 1972, s: 101-102).

Kültürel bir öğe olarak müziğin insanlık tarihiyle eşzamanlı olarak ortaya çıtı̆̆ varsayılmaktadır. Anadolu'da müziğin ilk yazılı örnekleri Sümerlere aittir. M.Ö 4. bin yıllarında Mezopotamya'ya göç eden ve M.Ö 3200 yıllarında yazıyı icat ederek Mezopotamya'yı yazılı tarih sahnesine çıkaran bu toplum, müzik tarihi açısından da çok önemli bir yer teşkil etmektedir (Kınacı, 2012, s: 11).

Ali Esgin "Bir Müzik Sosyolojisi Var Mıdır?" çalışmasında müzik ve toplum ilişkisini şu şekilde aktarmıştır: İnsanoğlunun tarihsel manada, felsefi ve düşünsel sürecine baktığımızda, müziktoplum ilişkisi ilkçağlardan beri önem arz etmiştir. İlkçağ düşünürlerinden, Çin tarihinin en büyük düşünürü Konfüçyus'a göre "müziğin topluma karşı birincil sorumluluğu, duyguları arıtıp bireyleri 
uyumlu kılmasıdır". "Bir insan topluluğunun nasıl yönetildiğini öğrenmek isterseniz onun müziğine bakın" diyerek doğru müziğin, devleti doğru ve iyi yönetmekte belirleyici olduğunu belirtmiştir. İlkçağ dönemi düşünürlerinden Platon ve Aristoteles müziğin toplumsal bağlamının ölçütlerini oluşturmuşlardır. Platon için müzik, onun ideal devlet görüşünün merkez unsurlarından biridir. Ayrıca bireysel gelişmenin en önemli araçlarından biri olduğunu ve müziğin ruhu eğittiğini ifade etmiştir. Aristoteles ise müziği, arınma ve temizlenme anlamına gelen katharsis kavramı ile ilişkilendirerek, bireyin doğru ahlâka ulaşması, iyiye yönelmesi ve kendini eğitmesinde başvuru kaynağı olarak göstermektedir (Esgin, 2012, s: 159-160).

İnsanoğlu tarih boyunca kendini güçlü ve iyi hissetmek için müzikten, yeteneğinin ve aklının erdiği oranda hep faydalanmıştır. Ortaçağda hırıstiyanlığın ortaya çıkışıyla, alimâne denilen çok sesli kilise müziğinin karşısında halk müziğini Fransa'da Trourbabour Trouvere, jonleur, Menestrel, Almanya'da Minnesönger ve Maistersönger gibi adlar altında tanınan saz şairleri icra ve temsil ediyorlard1 (Ataman, 1946, s: 91).

Uygarlık tarihinin beşiği olan Anadolu'da, yukarıda görüşlerine yer verdiğimiz ve dünya düşünce tarihi içerisinde oldukça önemli yere sahip olan Konfüçyus, Platon ve Aristoteles'in müzik ile ilgili ifade ettikleri görüşlerini, Alevi-Bektaşi öğretisinin taşıyıcıları olan ozan, âşık ve zakirler, toplumsal bağlamda olduğu gibi pratiğe geçirmişlerdir. Yine Ortaçağ Avrupası'nda, Fransa'da Trourbabour Trouvere, jonleur, Menestrel, Almanya'da Minnesönger ve Maistersönger'in müziktoplum ilişkisi açısından yerine getirdikleri fonksiyonun başka bağlamda bir benzerini, Anadolu'da Alevi âşı ve ozanları yerine getirmişlerdir.

Müzik, her kültür için önemlidir, özeldir ve temel unsurlarından biridir. Zamana tanıklığı ve kendini koruyabilmesi, işlevselliği açısından ise çok daha önemlidir. İşte bu yüzden müzik, kültürü ve kültürel kimliği anlamada en önemli anahtarlardan biridir. Çağdaş etnomüzikologların çalışmaları, müziğin evrensel olmadığının ve işte bu yüzden kendi bağlamı içinde yorumlanması gerektiğini belirten Clarke, Hargreaves'den şu bilgileri aktarmıştır: "Herhangi bir kültürde nelerin "müzik" kavramını oluşturduğu sosyal bağlama ve araştırılan davranışın işlevine bağlıdır. Müziğin ifade ettiği deneyimler, fikirler ve duygulanımlar, tonal yapılar ve semboller, kültürel olarak görecelidir" (Clarke 2001; 128-129).

\section{Alevi-Bektaşi Öğretisi}

Alevi öğretisinin toplumların dikkatini çekecek biçimde ortaya çıkışı, 632 yılında Hz. Muhammed'in ölümüyle yaşanan halifelik sorunlarından sonra, İslam toplumunda ortaya çıkan sosyalsiyasal ayrışma ve vuku bulan Kerbela olayı ile olmuştur. Kerbela, yüzyıllara damgasını vurmuş, bir insanlık dramının tarihsel adı olarak tarihe not düşülmüş ve bu sadece İslam tarihinin değil, insanlık tarihinin de en kara ve acıklı sayfalarından biri olarak ifade edilmektedir.

Alevi kültürel kimliğinin en temel simgesi Hz. Ali, Ehl-i beyt ve On iki İmamlar'dır. Bunlar bütün farklı Alevi topluluklarının ortak paydasını oluşturmaktadır. Alevi topluluklarının varoluş nedenlerini ifade eden her türlü sözel ve yazılı ürün, onların kültürel kimliliğinin alt yapısını oluşturmaktadır. Bu sürecin oluşmasında, sözlü kültür ürünlerinin öğrenilmesinde ve aktarılmasında müzik önemli bir görev görmüştür.

Kendine özgü ritüelleri olan Alevi-Bektaşi düşünce ve inanç sistemi, Anadolu uygarllğg ve yeryüzü kültür bahçesinin binbir çeşit kültür mozaiğinin, benzeri ender görülen birleştirici ve bütünleyici, barışç1l bir öğesidir.

Hacı Bektaş Veli hümanist bir çizgide, hoşgörü temelinde, yaşamda değişimi öneren ve örgütleyen bir düşünce ve inanç sisteminin kurucusu olarak, "benim kâbem insandır" ilke ve felsefesiyle bu sürece 1şık tutmuştur. İnsanın düşünce dünyasına 1şık tutan Alevi-Bektaşi öğretisinin yarattığı bu kültür atmosferinde yetişen birey, sevgi ile yoğrulmuştur. İşte insanı insan yapan o 
sevginin merkezi serçeşme Hacı Bektaşı Veli'dir. O, müziği ve edebiyatı bu düşünce ve inanç sisteminin içine almıştır.

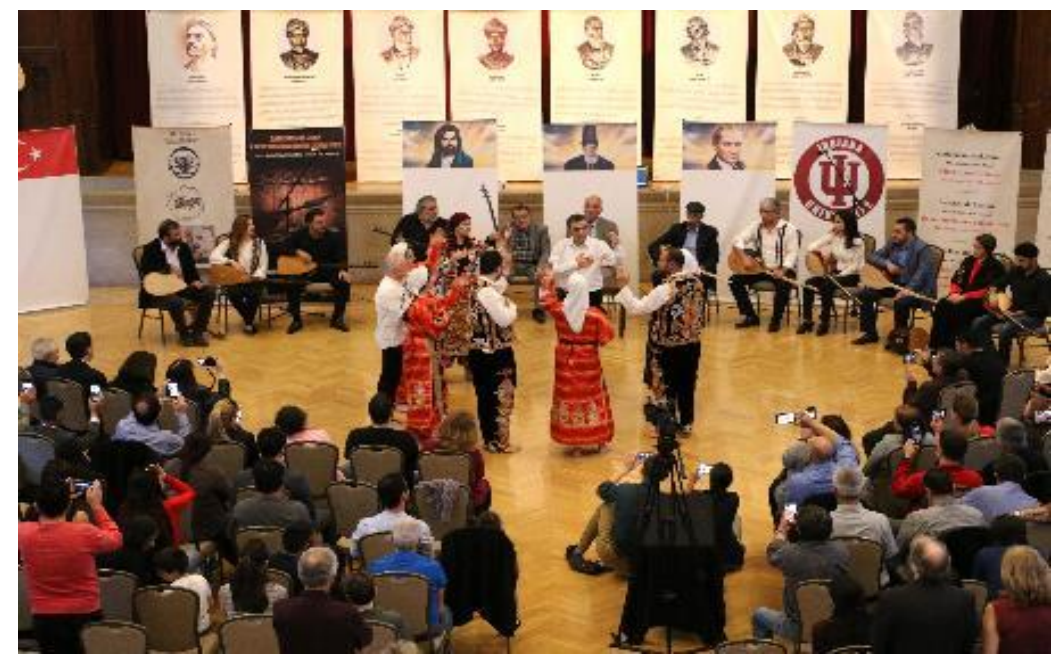

Resim 1. İndiana Üniversitesinde Cem Ritüeli

\section{Alevi müziği}

Alevi müziği saz ve söz birlikteliği üzerine kurulmuştur. Edebi bağlamını oluşturan temel unsur, öğretinin kodlarını taşıyan söz yapısıdır. Bu yapı, öğretinin tarihsel sürecini, felsefi ve mitolojik bağlamlarını şiirleştirerek anlatmaktadır. Müzikal bağlamı ise âşık, ozan ve zakirler tarafından, bağlama eşliğinde, şiirleştirilmiş edebi yapının içeriği üzerinden oluşturulmuştur. Alevi-Bektaşi topluluklarının yaşadıkları farklı bölgelerin, bölgesel farklılıklardan kaynaklı olarak sosyal etkileşim yoluyla oluşturdukları farklı ezgiler, aynı sözlerle, genellikle bağlamayla çalınıp söylenerek icra edilmiştir. Sosyal miras yoluyla kuşaktan kuşağa aktarılmış olan ve Alevi müziğinin temelini oluşturan bu birbirinden farklı müzikal yapı (ezgi-ritim-dizi) üzerine oturtulan aynı sözlerden oluşan Alevi müziği bugün de varlığını sürdürmektedir. Alevi müziğindeki tür ve biçim terimlerine hem şiirsel hem de müzikal manada olmak üzere iki anlam yüklenmektedir. Bu edebi ve müzikal biçimler şu şekilde tasnif edilmektedir:

Nefes: Dinî temlere bağlı âş̧k edebiyatı nazım şekillerinden ilahilerin Alevi-Bektaşi âşıklarınca söylenenlerine denir. Konusu genellikle tasavvuf, tasavvuftaki vahdet-i vücud, AleviBektaşi ilkeleri, tarikat kuralları ile ilgilidir (Yardımcı, 2014, s: 367).

Tevhit: Tanrı'nın birliği anlamına gelen Tevhit; Alevi-Bektaşi öğretisinden Hz.Ali'in Tanrı'nın velisi olduğunu anlatan şiir ve müzik türüdür (Korkmaz, 2005, s: 685).

Düvaz-ı İmam: Farsça 'Düvazdeh' kısaltılmış şekli 'Düvaz' 'On iki' anlamına gelmektedir. Cem törenlerinde okunan ve içinde on iki imamın adlarının sırasıyla geçtiği şiirlere 'Düvazdeh İmam', 'Düvaz-İmam' yada kısaca 'Düvaz' denir (Gölpınarlı, 1992, s: 46).

Miraçlama: Hz. Muhammed ile Hz. Ali'nin Kırklar Meydanı'nda buluşmasını anlatan ve epik bir karakter gösteren Alevi-Bektaşi şiir ve müzik türü.

Semah: Alevi-Bektaşi topluluklarının kendi inançları doğrultusunda her hareketinde özgün bir mânâ taşıyan, beden dilini kullanarak sergiledikleri Hakk'a ulaşma biçimini ifade eden şiir ve müzik türünün genel ismidir. Semah, aleviliğin temel ibadeti olan cem ayininin ayrılmaz bir unsurudur. Genellikle bağlama ile icra edilen kendine has bütünselliği olan müzik ve söz eşliğinde kol ve ayak figürlerine dayanan mistik bir danstır. 
Semahın kökenini anlamak için cem ayininin kökenine bakmak gerekir. Yaygın inanışa göre Ayin-i Cem; Miraç yolculuğu sırasında Hz. Muhammed'in vardığı 'Kırklar Meclisi' ya da 'Kırklar Sofrası'nda, zamanın dışında, Arş'ta gelişen olayların (ki buna Kırklar Cemi denmektedir) yeryüzünde taklidi-canlandırılmasıdır. Burada 'Kırklar' adıyla anılanlar, Hz. Muhammed'in ve Hz. Ali'nin de aralarında bulunduğu 'kırk ulu kişi', 'kırk kutsal kişilik'tir. Bir başka inanış ise, 'kırk kavramı' ya da 'kırk sembolü'nü, yani bir anlamda aleviliğin sırrını 'Doğum' ile, 'Doğuş' ile ilişkilendirmektedir. Bu inanışa göre Alevilikle ilgili tüm sembol kavramlar doğum ile ilgili, üreme ile ilgili ve insana ilişkin kavramlardır. 'Batın' kavramı ise sırrı saklamak için kullanılır. Kırklar Cemi ve Semah insanın anne rahminde mayalandığı ve bütün azaların belirginleşip (üçyüzaltmışaltı aza) çokluktan birlik, yani bireyin oluştuğu ilk kırk gün ile ilgilidir (Öztürk, 2005, s: 240).

Mersiye: Daha çok Hz. Hüseyin'in Kerbelâ'da öldürülmesinin anlatıldı̆̆ı epik karakterli Alevi-Bektaşi müziği ve şiiri türü (Duygulu, 1997, s: 12).

Deyiş: Öğretici, eğitici, öğüt verici konuların yanında daha çok Alevi- Bektaşi müziği ve edebiyatında dinî, tasavvufî inancı ve tarikatın ilkelerini anlatan şiirlerin genel adıdır (Duygulu, 1997, s: 8).

Şathiye: Dinin ilkelerinden, inançlardan teklifsizce ve alaycı bir dille söz ediyormuş gibi söylenen şiirlere denir. Bu şiirler, aslında toplumun ve insanların eleştirisini yapmakta ve tasavvuf kavramlarını anlatmaktadır. Bu şiir türüne genellikle Bektaşi şairlerinde rastlanmaktadır (Özdemir, 2007, s: 210). Bir edebi tür olan şathiye aynı zamanda bir müzikal formdur. Ancak müzik yapısı olarak kalıplaşmış bir ezgi yapısı yoktur. Genellikle deyiş̧ formunda seslendirilirler.

Devriye: Alevi-Bektaşi şiirinde devriye, "Devir öğretisini konu edinen, insanın sonsuz gerçeklikten gelip, değişik aşamalardan geçip yine oraya varacağını anlatan şiir" türüdür (Korkmaz, 1993, s: 98). Aynı zamanda bir müzikal form olan devriyeler müzik olarak deyiş formunda seslendirilirler.

Methiye: Alevi-Bektaşi edebiyatında methiye, Hz. Ali başta olmak üzere ağırlıklı olarak Alevi-Bektaşi geleneğinin kurucusu, yaşatıcısı, taşıyıcısı olan erenlerin ve yol önderlerinin övüldüğü şiirlerdir. Methiyelerde aynı zamanda Alevi-Bektaşi geleneği ve anlayışı da aktarılmaktadır. (Gölpınarlı, 1992, s: 104). Methiyelerde bir müzik formu olarak ezgi ve ritim yapısı deyiş formunun özelliklerini taşımaktadır.

Nevruziye: Farsça yeni gün anlamına gelen nevruz Alevi-Bektaşilerce Hz. Ali'nin doğduğu gün olarak kabul edilmiş̧ir. Nevruz günü 20 Mart'ı 21 Mart'a bağlayan gece, cem töreni yapılır ve gülbanklar, nefesler özellikle nevruziyeler söylenir ve semah dönülür (Korkmaz, 2005, s: 517-518). Nevruziye müzikleri çoğunlukla deyiş ve nefes formundadır. 


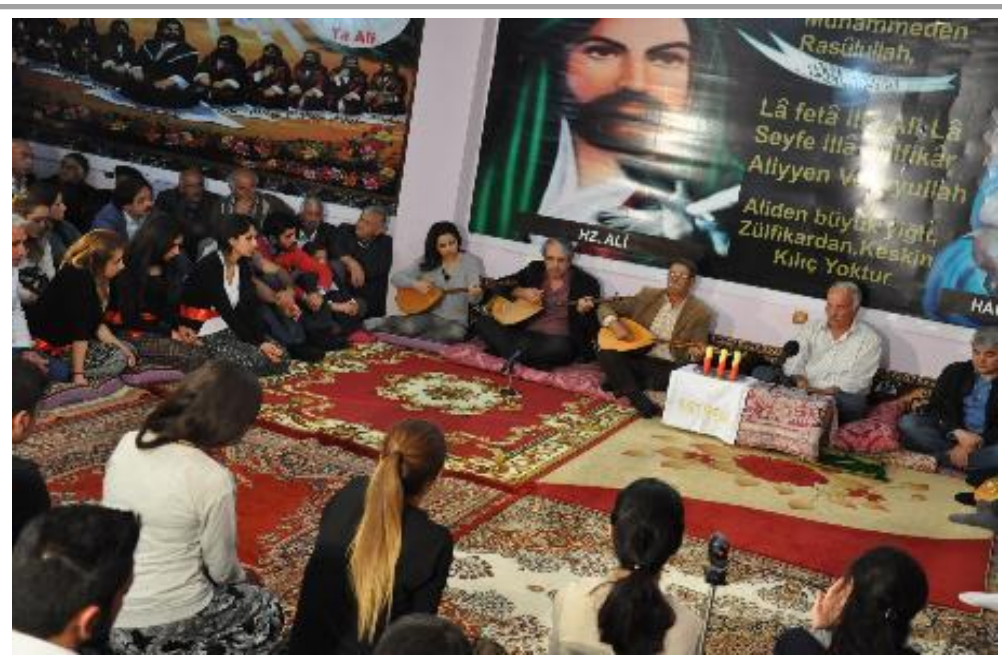

Resim 2. Cem Ritüelinde Müzikii

\section{Bağlama}

Bağlamanın tarihçesi ile ilgili iki farklı görüş ileri sürülmektedir. Gazimihal'in aktarmasına göre bağlama, Orta Asya Türk kültürüne ait kopuz ile ilişkilendirilmektedir. Anadolu'da kopuz 17. yy. sonlarında bağlama adını alır. Bağlamanın atası olduğu belirtilen kopuz, yaylı ve yaysız olmak üzere iki ayrı biçimde kullanılmış ve halk tarafından kutsallık payesi verilmiş eski telli çalgılar grubundandır (Gazimihal, 1975, s: 106).

Bir diğer görüşe göre ise bağlamanın aslında Hititlere özgü kutsal bir saz olduğu ve Karkamış kabartmalarında sapından sallanan püskülüne varıncaya dek bütünüyle bağlama şeklinde olduğu görülmüştür (Birdoğan, 1988, s: 77). Çankırı'nın güneyindeki İnandık'ta bulunan bir kült vazoda karşılıklı çalpara çalan iki kadın arasında ve ayakta saz çalan bir erkek, Çorum Boğazköy'de ve Yozgat Alişar'da ele geçen vazo parçalarında resmedilmiş saz çalan adam ile Gaziantep Karkamış orthostatlarında görülen saz çalan müzisyen görüntülerindeki bağlamanın şekli ile çalış şekli Hititolog Sedat Alp'in ifadesiyle "Anadolu halk ozanlarının kullandığı sazla yakın bir benzerlik taşımaktadır" (Alp, 2011, s: 70-74). Bu bulgular 1şı̆̆ında Anadolu'da Orta Asya'dan gelen kopuzdan daha öncesine ait bir saz şeklinin varolduğu ve bunun bağlamanın atası olduğu kanatine varılmış ve bağlamanın Orta Asya kaynaklı değil Anadolu kökenli olduğu ve Hititlerden bugüne gelen bir saz şekli olduğu düşüncesi ortaya çıkmıştır.

Bağlama, zaman içinde medeniyetler beşiği Anadolu'da pek çok kültürün etkisinde kalarak gelişim ve değişim sürecine girmiş gerek yapısı gerek çalış biçimi gerekse duygusuyla Anadolu'ya ve Anadolu insanına özgü bir saz olmuştur.

Zamanda derinlik, mekânda yaygınlık bağlamında geniş bir coğrafi alana, yüz yıllara dayanan uzun bir zaman dilimi içerisinde yaygınlaşmış olan bağlama, Balkanlardan Kafkasya ve Orta Asya'ya kadar uzanan topraklarda değişik isimler ve formlar almakla birlikte (divan, meydan, dütar, çöğür, rebap, ırızva, tambura, ikitelli, cura vb) genel olarak 'saz' ismiyle Türk kültürünün ayrılmaz bir parçası olmuştur. "Kopuz, ismiyle ve cismiyle tarihsel süreç içerisin de, bulunduğu coğrafyalarda ve onu kullanan toplulukların, yaratıcılığına, eser ve ezgilerine göre şekillenmiş̧tir" (Feyzioğlu, 2006, s: 224238 ). Alevi toplumunda bağlamaya dede sazı veya balta bağlama adı verilmektedir. Balta bağlama, tekne şekli yaygın olan bağlama formundan daha farklıdır, teknenin arka kısmı balta ağzını andırmaktadır ve ismini de buradan almaktadır. 


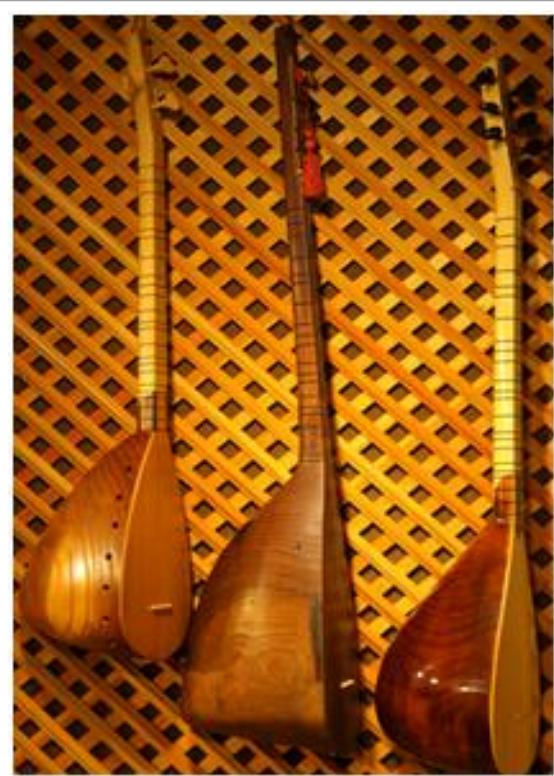

Resim 3. Balta Saz (Dede Sazı) ${ }^{\text {iii }}$

Tarihsel süreç içerisinde eski Türk topluluklarının yapısı incelendiğinde, sosyal yaşamda önemli bir konumda yer alan kam, baksı ya da ozanların en önde gelen özellikleri "Kopuz ya da saz çalarak, halk ozanlığı ya da hikâyeciliği yaparak" toplumsal sorunlara değinmeleridir (Köprülü, 2005, s: 28-29)

Anadolu'da Alevi-Bektaşi anlayışının ilk kalıcı ve etkili izlerini bırakmış olan ve düşünsel boyutun derin, anlam yüklü eserlerinin ozanı olan Yunus Emre (13.yy) bağlamanın atası olan kopuzu şöyle dile getirmiştir:

$$
\begin{aligned}
& \text { Yunus imdi Süphan’1 vasfeylegil gönülde, } \\
& \text { Ayrı değil ariften bu kopuz ile çeşte, } \\
& \text { Yunus Em } \\
& \text { Ben Oruç namaz içün } \\
& \text { Süci içtim esridüm } \\
& \text { Tesbih ü seccadey'çün } \\
& \text { Dinledim çeşte, kopuz }
\end{aligned}
$$$$
\text { Yunus Emre (Eyüboğlu, 1991, s: 31). }
$$

Yunus Emre (Birdoğan, 1988, s: 78).

Batı dünyasında etkin olan toplum-sanat ilişkisi rönesans ve reform sürecinde oldukça etkili olmuştur. Aydınlanma döneminindeki büyük değişimler, müziksel algı ve pratikler üzerinden toplumsal amaca araçlık yapmıştır. Netice itibarıyla bilim ve sanattaki yenilikler insanoğlunu bir çağdan başka bir çağa taşımıştır. Dünya düşünce tarihi içerisinde oldukça önemli bir yere sahip olduğu düşünülen Alevi kültürü, var olma ve aydınlanma mücadelesini de sanat ile gerçekleştirmiştir. İletişimin en önemli kanallarından biri olan sanat, kişisel, toplumsal ve kültürel bağlamdaki iletişim sürecinde önemli bir işleve sahiptir. İnsanoğlu yaşadığı her çağda ve bulunduğu her yerde bir ifade biçimi olarak sanatı kullanmıştır. 
Alevi müziğinin temel sazı olan bağlama, sanatsal iletişim bağlamında taşıdığı iletiyi görsel, işitsel ve duygusal manada alıcıya ulaştırır. Bağlama, iletinin içerik anlamını müziksel duyguyla pekiştirerek ve ruhsal bir atmosfer yaratarak, kolay algılanması ve bellekte kalıcılığını sağlaması açısından önemli bir işleve sahiptir. $\mathrm{Bu}$ sanatsal iletişim sürecinde, Alevi-Bektaşi kültürünün âşıklarının, ozanlarının, zakirlerinin dilinden ve telinden bağlama eşliğinde tekrarlanan öğretiler ve ritüeller yoluyla sözlü kültür üzerinden öğretinin kültürel belleği oluşturulmuş ve geleceğe aktarılmas1 sağlanmıştır. Ong'un, "Dünyadaki başka kültürlerin binlerce yıllık oluşturduğu deneyimini söz söyleme, söyleneni dinleme, dinleneni tekrarlama ve yeniden inşa etme yöntemi ile geçmişten geleceğe taşıması" olarak ifade ettiği yöntem tam da Alevi-Bektaşi toplumunun geçmişten günümüze gerçekleştirdiği yöntemle paralellik göstermektedir (2010, s: 21).

Alevi kültürü, müzikle, şiirle ve dansla örülü geleneklerinde, bu üç ayrı sanat dalında kendine has bir üslup ortaya çıarmıştır. Derin bir anlam dünyası ve çeşitlilikle örülü şiir ve müzik birikimi nedeniyle, bağlama üzerine kurulu zengin bir mirasın oluşturulmasını da kaçınılmaz kılmıştır.

Ses nasıl insanın karakterini simgeliyor, ruhunu ifade ediyor ve kişiye bir ayna görevi görüyorsa, bağlama da Alevi toplumunun karakterini simgeleyip onların ruhunu ifade eden ve kültürel kimliklerinin temsiliyetini üzerinde taşıyan bir enstrüman olmuştur. Banu Mustan Dönmez'in aktardığı, Irene Markof'un, 2002'de kaleme aldığı bir çalışmasında, "Bağlama Alevilerin grup kimliklerinin ve itikatlarının güçlü bir simgesidir" şeklinde ifade edilmiştir (Dönmez, 2015, s: 57).

Sanat, dünyada birçok kültürel aktarımın öncü taşıyıcısı olmuştur. Bu anlamda Alevi âşık, ozan ve zakirleri de müzikal bir tema ve estetik algı içinde, sesin karakterini olușturan temel özellikleri bağlama eşliğinde eserlerinde kullanarak, topluma cesaret, umut ve heyecan vermişlerdir. Sesin sakinleştirici, tedavi edici ve mutluluk verici özelliklerinin yanı sıra, etkileyici ve hareket verici özelliklerinden de faydalanmışlardır. Ayrıca sesin insanı fiziksel düzlemden alıp yükselten ve mutlu kılan özelliği ile insan ruhunun derinliklerine hitap ederek hem ilham almışlardır hem de ilham kaynağı olmuşlardır.

Alevi kültürünün yüzyıllardır en temel bileşenlerinden biri olan bağlama ile öğretinin kodlarını taşıyan eserlerin çalınıp söylenmesi, kültürün canlandırılmasında, geleceğe aktarılmasında ve temsilinde oldukça önemli bir görev üstlenmiştir.

Bağlama, kutsi bir temsiliyeti olan dede ya da cem âşı̆̆ tarafindan çalıp söylenen deyişler ve semahlar aracılığı ile cem ortamına girmiş ve kutsal bir çalgı olma vasfını kazanmıștır. Şaman inancında kopuza yüklenen kutsiyeti belirleme açısından bulunabilen en eski kaynak 'Dede Korkut' kitabıdır. Bu kaynakta geçen bir ifade şu şekildedir: "Eğer elinde kopuz olmasaydı ağam başı için seni iki pâre kilur idim" (Birdoğan, 2006, s: 437). Alevi toplumunda, bağlamanın kutsiyeti şamanlardakine benzer bir paralellik göstermektedir. Bu bağlamda bağlama İmam Ali'nin ve Ali'nin ilkelerinin maddi bir temsilidir. Akustik olarak sesin tınladığı ve titreştiği yer olan bağlamanın teknesi, Ali'nin gövdesi ile özdeşleştirilmiştir. Sapı Ali'nin kılıcı Zülfikar'ı, on iki teli-bazen on iki perdesi, On iki İmamları ve tellerin en bas sesli olanı ise Peygamber Muhammed'i temsil etmektedir (Dönmez, 2015, s: 57).

Genel anlamda her bölgede, bağlamanın icra edilmesinin öncesinde ve sonrasında (AllahMuhammed-Ali) üçlemesiyle öpülerek başa konulması ve özenle saklanması bağlamaya atfedilen bir başka simgesel kutsiyeti ifade etmektedir.

16.yy halk ozanı Pir Sultan Abdal sazın Alevi öğretisindeki yerini, bir dörtlüğünde şöyle anlatmaktadir:

Ben Hakk'ın ednâ kuluyum

Kem damarladan beriyim

Ayn-1 cem'in bülbülüyüm

Meydana ötmeğe geldim

Pir Sultan Abdal (Eyüboğlu, 1993, s: 123). 
Alevi öğretisinde bağlamaya atfedilen kutsal nitelikler araştırmacı yazar Nejat Birdoğan tarafından şu şekilde ifade edilmiştir: “Bağlamanın teknesi gizli bilimler ve Tanrı'yı bulmaya yarayan bir hazinedir. Bu nedenle buraya 'Bilim şehri' denir. Göğüs kısmı seslerin çıkmasını sağlar ve bu göğüs, teknedeki gizli bilimlerin bozulmasını, kaybolmasını önleyen kapı durumundadır. Eşik, alevilikte zaten kutsal olduğu için, saz eşiği de bu nedenle ayrı bir önem taşır. Elif biçimindeki sap, bu yapısından dolayı Ali'ye ve Allah'a değinmedir. Sazın üzerindeki karar sesi La perdesi 'şah perde' adını taşır. Ara nağmeleri bulmaya yarayan fa, sol, la seslerinden ilk ikisi anımsatma ve arama perdeleri olduğundan 'niyaz perdesi' adını alır. Aleviler sazı, âşık ve ozanların hikmetli sözlerine aracılık ettiği için, 'Telli Kuran' olarak adlandırırlar. Gönülden ele, elden tele, telden dile ve dilden, gönüle döngüsü ile şah perdesi (karar sesi)'ne dönüş olur."

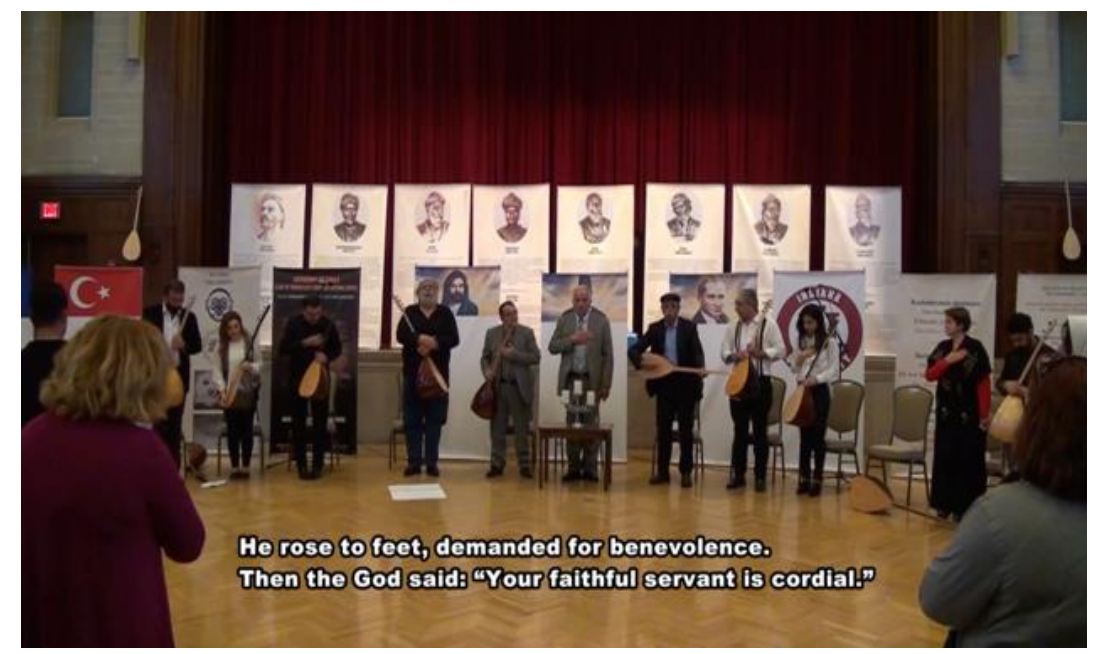

Resim 4. İndiana Üniversitesi Cem Ritüelinde Bağlama Eşliğinde Miraçmane Eserinin İcrasi ${ }^{\text {iv }}$

Bana Hakk'1 soran oğul

Haber al aşık sazından

Göğsü peygamber ağacı

Kıl1fi Ali bezinden

Elif, Hakk'a nişan sapı

O gerçeğe açar kapı

Eşikten başlayan yapı

Sarı turna avazından
Şah perdeye basan parmak

Niyaz eyler Hakk'a varmak

Ezgi olup akan 1rmak

Hak imamlar düvazından

Sancilar dolunca cim'e

Baş eğerek gelir cem'e

Elbette sarilır dem'e

Acisı canan nazından
Sıtk ile daya bağrına

Derman yetirir ağrına

O sultanın diyarına

Hisse götürür sızından

Cevri, budur dilli Kur'an

Hem erkanlı yollu Kur'an

Elimizde telli Kur'an

Yürürüz dostun izinden

(Birdoğan, 1995, s: 252).

Bağlama Alevi kültüründe, birinci aşamada kültürel aktarım, ikinci aşamada ise kültürel yaygınlık alanında temel bir işlevsellik göstermiştir. Kültürel aktarım sürecini cem ritüelleri ve öğretisel bağlamdaki mekteb-i irfan muhabbetleri üzerinden gerçekleştirmiştir. Kültürel yaygınlığı ise müzik ve edebiyatı yaşam pratiği içerisinde içselleştirmiş olmanın da farkındalığıyla Alevi öğretisinin kendi içinde yetiştirdiği, ileri icra düzeğindeki performans sanatçıları tarafından çalınıp söylenen öğreti içerikli eserler yoluyla yapmıştır. Toplumsal, kültürel ve kişisel kimliğin inşası ve performansın bu süreçteki önemi, yirminci yüzyılın son yıllarında hem performans hakkındaki kuramsal yazılarda hem de performanslarda en önemli meselelerden biri olmuştur (Carlson, 2013, s: 81). 
Kültürel aktarım boyutunda, eserlerin mesaj içeriği, bağlama icrasına göre daha dominant iken, kültürel yaygınlık boyutunda, bağlama icrasının teknik niteliği daha dikkat çekmektedir. $\mathrm{Bu}$ durum, bu eserler üzeriden bağlamayı ilgi ve odak noktası haline getirmektedir. Ali Ekber Çiçek'in 20. yüzyıl âşıklarından Amasyalı Âşık Sıtkı Baba'nın şiiri ile müziklendirdiği 'Haydar' isimli eseri, kültürel yaygınlık açısından bağlamanın teknik çalım boyutunun dikkat çekiciliğine örnek gösterilebilir.

Ondört bin yıl gezdim pervanelikte

Sitk1 ismin buldum divanelikte

İçtim şarabını mestanelikte

Kırkların ceminde dara düş oldum (Âşık Sıtkı)

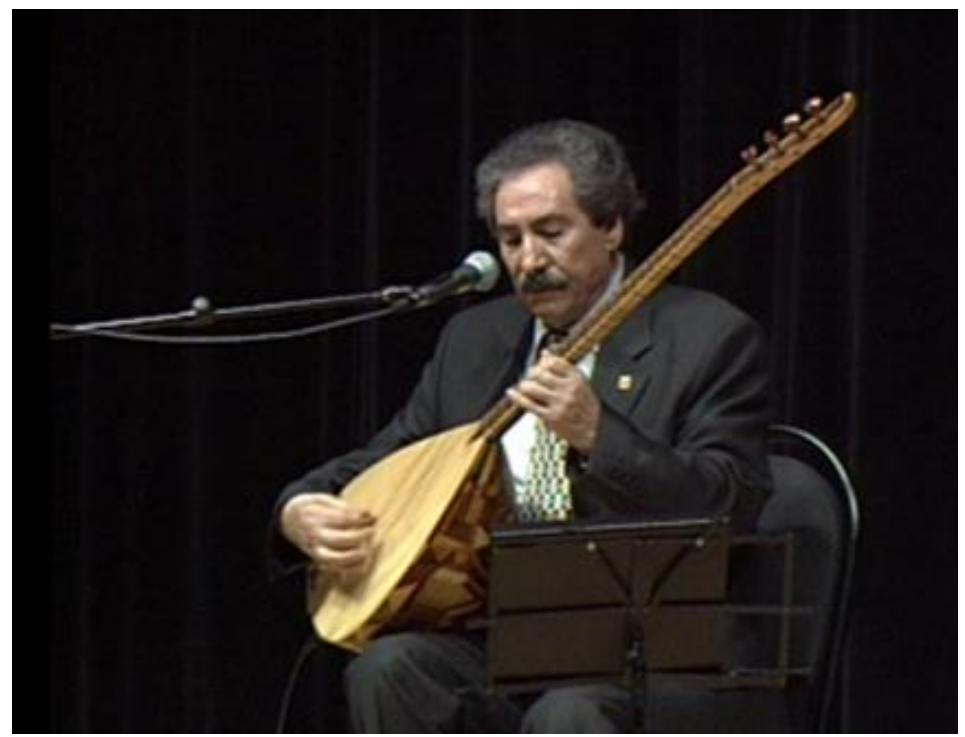

Resim 5. Ali Ekber Çiçek ${ }^{\vee}$

Bunun gibi öğretinin kültürel kodlarını taşıyan bir çok eserin, bağlama ile ileri icra düzeyinde icra edilmesiyle, Alevi müziği ve kültürünün ulusal ve uluslararası arenada yaygınlaşması sağlanmıştır.

Bağlamanın Alevi kültüründeki yeri ve öneminini vurgulamak açısından Amasya'nın Hamamözü ilçesinin Yemişen Köyü'nde, Gani Pekşen ve Ali Cem Akbulut ile birlikte bulunduğumuz bir derleme çalışması sırasında, bizzat yaşadığım bir diyaloğu ve anlatıyı aktarmak isterim: 26 Nisan 2013 tarinde Âşık Veli Balcı ve Âşık Abdullah Balcı ile yaptığım görüşmede, Âşık Abdullah Balcı'ya yönelttiğim "sazı nasıl ve neden öğrendiği” sorusuna verdiği yanıt, Alevi anlayışını ve düşünce biçimini ortaya koyan tarihi bir nitelik taşımaktadır. Âşık, bir an için geçmişi anımsayarak ve gözleri dolarak şöyle anlattı: "Oğlum ben daha on dört yaşındaydım babam ile birlikte köyde bir dügüne gittik, düğünde yaşıtlarım ellerinde tabancalar ile havaya ateş ediyorlardı, onlara çok özendim. Çocukluk işte, ben de tabancayla havaya ateş etmek istiyorum. Dügün dönüşü babama dedim ki, 'Baba ben de arkadaşlarım gibi tabanca kullanmak istiyorum, bana tabanca alır mısın?' Babam da bana, 'Tabii oğlum, alırım ancak ondan önce senden bir isteğim var' dedi ve ardından da 'Şu sazı al bu deyişleri öğren çal, benden sana söz, tabanca alacağım oğlum' dedi. Bunun üstüne beni köyümüzde zakirlik yapan dedeye götürdü. Ben de heyecanla hemen babamın isteğini yerine getirerek tabanca almak için çalışmaya başladım. Aradan tam iki yıl geçti ve babamın benden istediği Alevi cemlerinde 
çalınıp söylenen deyiş, semah ve duazları öğrendim ve babama koşarak 'Babacığım senin bana verdiğin bütün eserleri artık çalabiliyorum!' dedim ve beni sınav yapmasını istedim. Babam beni dikkatle dinledi ve 'Aferin oğlum çok güzel çalıp söylüyorsun, şimdi ben de sana verdiğim sözü tutarak sana tabanca alacağım' diyerek ayağa kalktı. Ben de ayağa kalktım ve babama dedim ki: 'Ya babacığım bu sazı çalıp, bu deyişleri söyleyen adam daha tabancayı ne yapsın?' O da bana döndü ve 'Desene oğlum sen adam olmuşsun!' dedi.

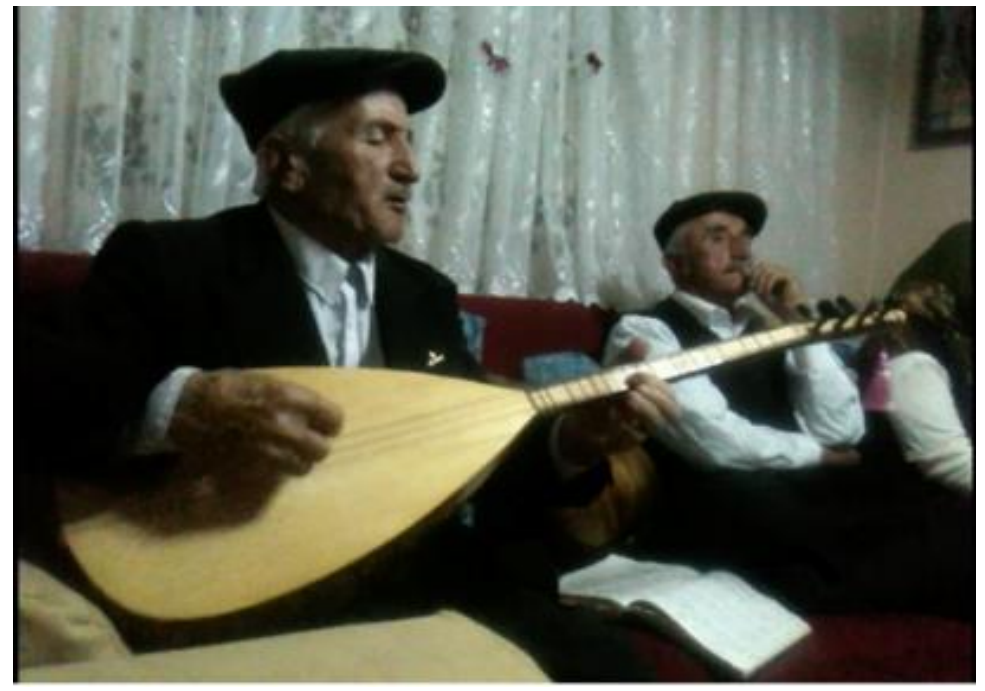

Resim 6. Âşık Abdullah Balcı ve Âşık Veli Balcı vi

Amasya'nın bir Alevi köyünde, baba oğul arasında geçen bu olay aslında bize, bir gerçek silahın, bağlamayla nasıl yok edildiğini ve Alevi öğretisinin sanat yoluyla nasıl insan-1 kâmil ve barışçıl bir toplum yaratığının da en büyük göstergelerinden biri olmuştur. Bu durum 13.yy'dan günümüze bağlamanın Alevi kültüründeki yeri ve önemini bir defa daha ortaya koymuştur.

\section{Sonuç Yerine}

Alevi kültürel kimliğinde bağlamanın yeri ve önemi incelendiğinde, merkezine insanı koyan Aleviliğin, inanç ve kültür senteziyle oluşmuş bir yaşam biçimi üzerinden sanatsal bir varlık gösterdiği tespit edilmiş ve Alevi öğretisinin düşüncesiyle, felsefesiyle, müziğiyle, edebiyatıyla, şiiriyle, folkloruyla ve insansal değerleri ile dünya düşünce tarihi içerisindeki yerini almış olduğu görülmüştür.

Alevi öğretisinde, cemlerin saz ile müzik eşliğinde yapılıyor olması ve insan duyguları üzerindeki etkilerinden dolayı, bağlamanın ritüelin en temel unsurlarından biri olduğu anlaşılmıştır. Alevi kültüründeki cem ritüellerinde, bağlama eşliğinde icra edilen müzik aracılığıyla, kültürel aktarımın yanı sıra bireyin kimlik, kişilik, düşünsel ve inançsal gelişimi de sağlanmıştır.

Anadolu'da Alevi kültürünün, sanatsal iletişim yolu ile, cem ritüeli aracılığıyla aktarılmasının ve kamuda yaygınlaşmasının en önemli temel taşıyıcılardan birinin bağlama olduğu tespit edilmiştir.

Bağlamanın tarihsel süreç içerisinde, öğretideki konumu, taşıdığı misyon ve fonksiyonelliği nedeniyle, Alevilerin kültürel kimliklerinin temsiliyetini üzerinde taşıyan bir 'simge' olduğu kanaatine varılmıştır. Alevi müziğinin bölgesel farklılıklardan kaynaklı müzik yapısının ortak paydasının söz unsuru olduğu tespit edilmiştir. 
Bağlamanın Alevi kültüründeki kutsiyetini, Alevi âşık ve ozanlarının, Alevi kültürel kimiğinin en temel simgeleri olan Hz. Ali'yi, On iki İmamı ve Ehl-i beyt'i eserlerinde çalıp söyleyerek yaşatmaları ve aktarmaları ile sağlamakta olduğu tespit edilmiştir.

Alevi kültürel kimliğinde bağlamanın, bir çalgı olmanın çok ötesinde Alevi öğretisinin sanat yoluyla aktarılması ve bu yolla insan-1 kâmil ve barışçıl bir toplum yaratılması sürecinde önemli ve büyük bir rol üstlendiği görülmüştür.

\section{Notlar}

i Yusuf Benli özel arşivinden "Amerika İndiana Üniversitesi 13 Nisan 2017 Cem ritüeli"

ii Yusuf Benli özel arşivinden "Amasya Göynücek Kertme Köyü Nisan 2016 Cem töreni"

iii Yusuf Benli özel arşivinden "Balta saz (Dede Sazı) Koleksiyonu"

iv Yusuf Benli özel arşivinden "Amerika İndiana Üniversitesi 13 Nisan 2017 Cem ritüeli"

v Yusuf Benli özel arşivinden "Ali Ekber Çiçek fotoğrafi"

vi Yusuf Benli özel arşivinden "26 Nisan 2013 tarihinde yapılan Amasya ili derleme gezisi sırasında yapılan görüntülü görüşme"

\section{KAYNAKÇA}

\section{$\underline{\text { Kitaplar }}$}

Alp, S. (2011). Hitit Güneşi, Tübitak Popüler Bilim Kitapları, Ankara.

Ataman, A. M. (1946). Musiki Tarihi, M.E.B. yayınları, Ankara.

Birdoğan, N. (1988). Notalarıyla Türkülerimiz., İstanbul: Özgür Yayın Dağıtım.

Birdoğan, N. (2006). Anadolu'nun Gizli Kültürü Alevilik, Kaynak Yayınları, İstanbul.

Birdoğan, N. (1995). Anadolu Aleviliği Yol Ayrımında, Mozaik Yaynları, İstanbul.

Carlson, M. (2013). Performans, Dost Kitabevi Yayınları, Ankara.

Dönmez B.M. (2015). Alevi Müzik Uyanışı, Gece Kitaplığı Yayınları, Ankara.

Duygulu, M. (1997). Alevi-Bektaşi Müziğinde Deyişler, İstanbul: Pan Yayıncılık

Eyüboğlu İ. Z. (1991). Alevi Bektaşi Edebiyatı, Der Yayınları, İstanbul.

Eyüboğlu S. (1993). Pir Sultan Abdal, Cem Yayınları, İstanbul.

Fubini, E. (2006). Müzikte Estetik, çev: Fırat Genç. Ankara: Dost Kitabevi Yayınları

Gazimihal, M.R. (1975). Ülkelerde Kopuz ve Tezeneli Sazlarımı, Ankara Üniversitesi Basımevi.

Güvenç, B. (1972). İnsan ve Kültür, Atropolojiye Giriş, Sosyal Bilimler Derneği Yayınları, Ankara.

Gölpınarlı, A. (1992). Alevi-Bektaşi Nefesleri, İnkılap Kitapevi, İstanbul.

Korkmaz, E. (1993). Ansiklopedik Alevilik Bektaşilik Terimleri Sözlüğü, Ant Yayınları, İstanbul.

Korkmaz, E. (2005). Alevilik ve Bektaşilik Terimleri Sözlüğü, Anahtar Kitaplar Yayınevi, İstanbul.

Köknel, Ö. (1983). Kişilik, Altın Kitaplar Serisi, İstanbul.

Köprülü, M. F. (2005). Türk Tarih-i Dinîsi. Akçağ Yayınları, Ankara.

Köprülü, M. Fuad (2005). Edebiyat Araştırmaları C.I. Akçă̆ Yayınları, Ankara.

Ong, walter j. (2010) sözlü ve yazılı kültür, Metis Yayınları, İstanbul. 
Özdemir, A. (2007). Bütün Yönleriyle Türk Halk Edebiyatı Bilgileri. Bordo Yayınları, İstanbul.

Öztürk, Ü. (2005). Alevilerin Büyük Sirrl, Yurt Kitap-Yayın, Ankara.

Yardımcı, M. (2014). “Başlangıcından Günümüze Türk Halk Şiiri”, Kanyılmaz Matbaacılık, İzmir.

\section{Dergiler}

Clarke, G. L. (2001). “Alevi Kültürel Kimliğinde Müziğin Rolü”, Toplumbilim Müzik ve Kültürel Kimlik Özel Sayıs1 12, İstanbul.

Esgin, a. (2012). “Bir Müzik Sosyolojisi Var Mıdır?”, Doğu Batı Dergisi, Y11:15, Sayı:62, Ankara.

Feyzioğlu, N. (2006). Türk Dünyasında ve Anadolu'da Kopuz, A. Ü. Türkiyat Araştırmaları Enstitüsü Dergisi 31, Ankara.

Kınacı, M. (2012). "Eski Yunan Dünyasında Müzik ve Müzisyenler", Doğu Batı dergisi, yı1:15, Sayı: 62, Ankara. 